\title{
Performance Study about Electro-spark Depositing DK460UF Coating on Surface of Turning Tool
}

\author{
Huang Shao-hua \\ Da Lian Polytechnic University, \\ Da Lian, Liao Ning, 116034
}

\author{
He Feng-bao \\ Da Lian Polytechnic University, \\ Da Lian, Liao Ning, 116034
}

\author{
Wang Ming-wei \\ Da Lian Polytechnic University, \\ Da Lian, Liao Ning, 116034
}

\author{
Zhang Wei \\ Da Lian Polytechnic \\ University, \\ Da Lian, Liao Ning, 116034
}

\author{
Hu Jian-zhong \\ Da Lian Polytechnic \\ University, \\ Da Lian, Liao Ning, 116034
}

\author{
Pan Ren \\ Da Lian Polytechnic \\ University, \\ Da Lian, Liao Ning,116034
}

\author{
Chen Wen-qiang \\ Da Lian Polytechnic \\ University,
}

Da Lian, Liao Ning, 116034

\begin{abstract}
DK460UF is deposited on the surface of 9341 high-speed steel by DZ-4000(III) multifunctional surface hardening machine which use argon as shielding gas. They occur metallurgical reaction by electro-spark deposition technology to make electro-spark deposition migrate to the surface of the tool and form high-performance deposition layer with a strong and stable binding force of matrix. Under the process parameters: $2 \mathrm{~min}, 80 \mathrm{~V}, 3000 \mathrm{~Hz}, 150 \mu \mathrm{F}$, obtain the deposited layer which has no obvious defects such as micro-cracks and bubbles, thickness $89 \mu \mathrm{m}$, microhardness $1487.5 \mathrm{Hv}$. No clear boundaries exist in the deposited layer and the substrate. Transition zone thickness is greater than $20 \mu \mathrm{m}$.
\end{abstract} steel

Key words-electro-spark, cutting knife, DK460UF, high-speed

\section{INTRODUCTION}

With the rapid development of China's machinery manufacturing technology, the application of the tool is more wide. Machinery industry used to process the outer surface's tool is rasp, milling, planer, and turning tools and so on. Cutter is the most common one in the cutting tool. Turning tool is used on various lathes. Depending on the purpose, it can be divided into the thread cutter, flat knife, cylindrical knife, boring tools, cutting knife and so on. The cutting knife is a common turning tool, it is mainly used to cut grooves or cut workpiece.
Turning tool's material has hard alloy, high-carbon steel, high- speed steel. High speed steel tool has good toughness ,high impact toughness and good sharpening. But it is low hardness, red hardness is not high, easy to wear, and are generally used for low-speed cutting. When the parting tool cuts narrow and deep hole, chip is hard to discharge, easily blocked.

High-speed steel cutting knife are chosen as matrix specimen,the carbide DK460UF as electrodes. Detect sediments hardness, combined, thickness and acid resistance of tool.

\section{EXPERIMENTAL PROGRAM}

The experiment chose cutting tool model 9341(chemical composition shown in Table 1)which is producted by Shanghai Tools Factory whose size is $8 * 20 * 200 \mathrm{~mm}$. The deposition test is accomplished with DZ-4000(III) multifunctional surface hardening machine which is manufactured by surface engineering research laboratory of China Agricultural Machinery Institute. The electrode material is DK460UF whose diameter is $\varphi 4 \mathrm{~mm}$, chemical composition is $\mathrm{WC}-90 \%$, Co- $10 \%$. The bending strength is $3700\left[\mathrm{~N} / \mathrm{m} \mathrm{m}^{2}\right]$.

TABLE 19341 CHEMICAL COMPOSITION

\begin{tabular}{|c|c|c|c|c|c|c|c|c|}
\hline Element & $\mathrm{C}$ & $\mathrm{Si}$ & $\mathrm{Mn}$ & $\mathrm{W}$ & $\mathrm{Mo}$ & $\mathrm{Cr}$ & $\mathrm{V}$ & 其他 \\
\hline $\begin{array}{c}\text { Percentage } \\
(\%)\end{array}$ & $0.77 \sim 0.85$ & $0.20 \sim 0.40$ & $0.20 \sim 0.40$ & $8.50 \sim 9.50$ & $2.70 \sim 3.30$ & $3.60 \sim 4.20$ & $1.30 \sim 1.60$ & $\leq 0.060$ \\
\hline
\end{tabular}

Before experiment, the substrate and the electrode surface were washed with acetone to remove stains. Deposition, the electrode exposed to the protective cover $8-10 \mathrm{~mm}$, with the base body an angle of $45 \pm 15^{\circ}$. Argon as a protective gas, deposition selection of process parameters are shown in Table 2. 
TABLE 2 EXPERIMENT SCHEME

\begin{tabular}{|c|c|c|c|c|c|}
\hline $\begin{array}{c}\text { Experimental } \\
\text { position }\end{array}$ & $\begin{array}{c}\text { Deposition } \\
\text { time }(\mathrm{T} / \mathrm{min})\end{array}$ & $\begin{array}{c}\text { Voltage } \\
(\mathrm{U} / \mathrm{V})\end{array}$ & $\begin{array}{c}\text { Frequency } \\
(\mathrm{f} / \mathrm{Hz})\end{array}$ & $\begin{array}{c}\text { Capacitance } \\
(\mathrm{C} / \mu \mathrm{F})\end{array}$ & $\begin{array}{c}\text { Experimental } \\
\text { area }\left(\mathrm{cm}^{2}\right)\end{array}$ \\
\hline Rake face & 2 & 80 & 3000 & 150 & 1 \\
\hline main flank & 2 & 80 & 3000 & 150 & 1 \\
\hline auxiliary flank & 2 & 80 & 3000 & 150 & 1 \\
\hline
\end{tabular}

After the coating is completed, use wire cutting machine (DK7740) to cut the matrix which has coating deposition layer into $5 * 5 * 4 \mathrm{~mm}$ specimen, and then use Mosaic machine (XQ-2B ) to inlay it. Use metallographic grinding and polishing machine (MP-2C) to polish the specimen, with $4 \%$ nitric acid alcohol corrosion, time for $25 \mathrm{~S}$. Then utilize the automatic turret microhardness meter $(\mathrm{MHV}-1000 \mathrm{Z})$ to test the sediment' hardness, olympus (OLYMPUS-GX51) to observe sectional morphology.

There are many performance indicators of turning tools, such as wear resistance, corrosion resistance, high temperature resistance, high hardness and high toughness and so on.

\section{RESULTS AND ANALYSIS}

\section{A. Tool deposition layer thickness}

Fig. 1 is the growth trend graph of the thickness of the deposited layer every 20 seconds. The figure shows, sediment thickness curve upward trend.The acceleration of sediment increasing between zero and forty seconds is bigger than other time and its thickness grows faster. But the actual electrode material migration speed is constant. As in the process, the roughness of the surface of the desposited layer rapidly increases which causes the test thichness can not be effective utilized. in the process of 40-120s, the growth of the thickness of the base body acceleration tends to be reduced. This stage the roughness of the surface of sediment is stable. The increasing thickness due to the metallurgical reaction between the electrode material and the sediment material which can be regarded as effective thickness.

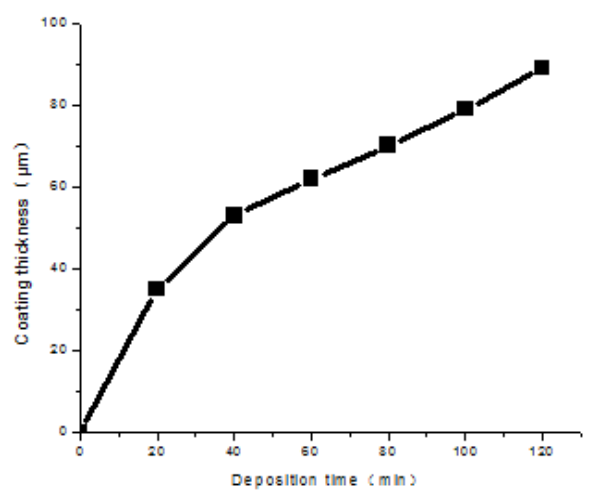

Fig. 1 Thickness of the coating

In order to adapt to the actual processing of the tool, use the oil stone to rub down the deposited layer into $40 \mu \mathrm{m}$ thick.

\section{B. Hardness of the tool sediments}

Fig. 2 shows the hardness changes chart which is tested by hardness meter. Fig. 3 reveals the hardness changes trend of the high-speed steel tool section.

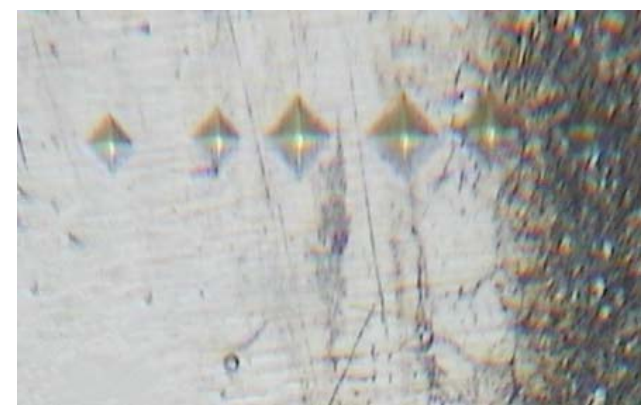

Fig.2 Tool section hardness

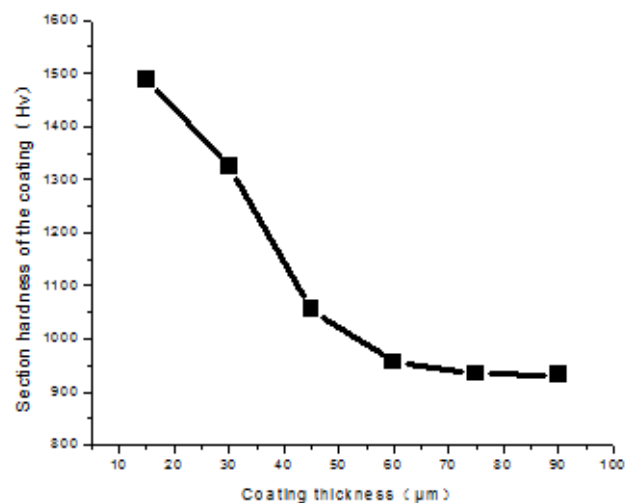

Fig. 3 section hardness of the coating

As can be seen from Fig.2 and Fig.3, the greater the distance from the deposited layer surface, the smaller of the hardness, the hardness of the deposited layer decreased. The surface material of the sediment is mainly DK460UF. Generated hard phase and carbides carbides improve the hardness of the deposited layer, the maximum $1487.5 \mathrm{Hv}$. The metallurgical integration and mutual penetration between the electrode material and the high-speed steel tool matrix material make the hardness on deposited layer close to matrix part drop rapidly. Be able to tell from Fig. 3 that the hardness of the deposited layer and the substrate hardness is almost the same $75 \mu \mathrm{m}$ away from the surface.

Comprehensive seen, the deposited layer away from the surface is less than $30 \mu \mathrm{m}$, the base material has no effect on the hardness of the deposited layer; 30-75 $\mu \mathrm{m}$, the hardness of the deposited layer rapidly decreased, so we call this region 
interlayer; more than $75 \mu \mathrm{m}$, the electrode material has small effect on the heat-affected of the matrix.

\section{Tool section morphology}

Fig.4 shows the binding morphology of the deposited layer and the base body of the lathe tool. After Whetstone grinding, you can see the sedimentary layer of the surface is relatively smooth, as it eliminated most sliver and protruding that affect the turning tool's performance which significantly reduces the surface roughness. It can effectively improve the machining accuracy of the lathe tool.

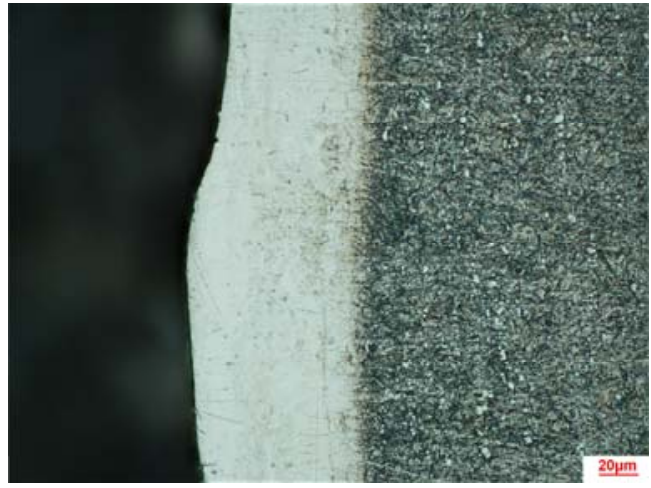

Fig.4 Tool section morphology
In Fig. 4, the bright layer is deposited layer of DK460UF. You can see the deposited layer forming of internal deposition electrode material and the matrix material mutual metallurgical reaction is preferably. Bubbles and micro-cracks, and other phenomena that do not appear to significantly affect turning tool performance which illustrates that layer shedding phenomenon will not appear in the actual use of the process of turning tools.

Gray region is the matrix dealt with nitric acid alcohol . Not apparent stratification phenomenon appears between the white bright area and the gray area (this area is a transition zone), but mutual penetration together about $20 \mu \mathrm{m}$ depth of penetration. During the deposition process, DK460UF electrode materials and high-speed steel substrate material occur metallurgical fusion. So it will not appear the sedimentary overall shedding. Comparative the displayed color of deposited layer and the substrate, we know the acid resistance of the deposited layer is much higher than the high-speed steel cutting tools matrix. It significantly enhance the acid resistance of the tool.

Comprehensive seen, DK460UF deposited layer and high-speed steel tool matrix merging does not appear stratification, not overall shedding, but also enhance the acid resistance of the turning tool surface.

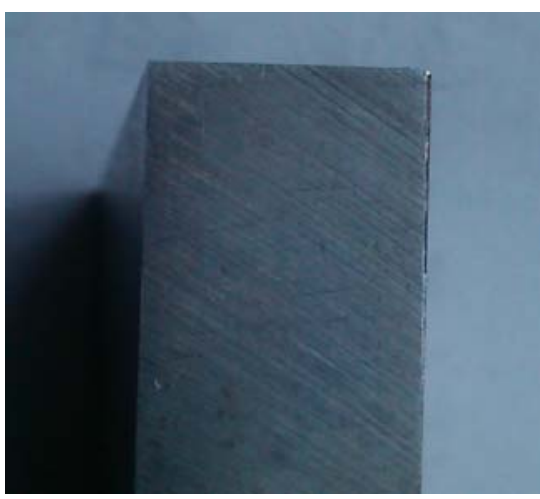

(a) Prior to the deposition

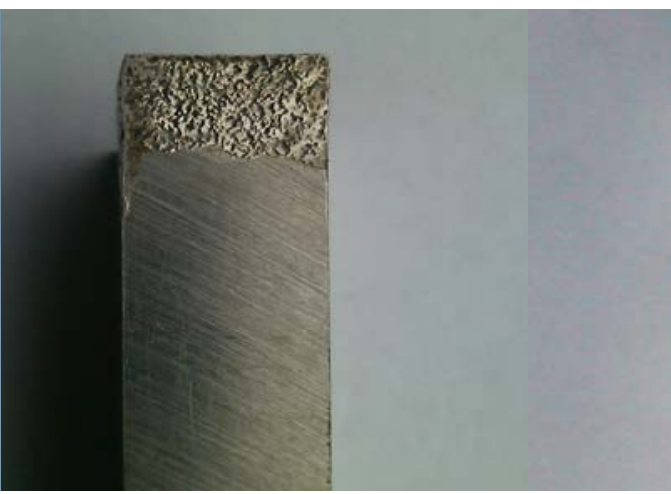

(b) After deposition

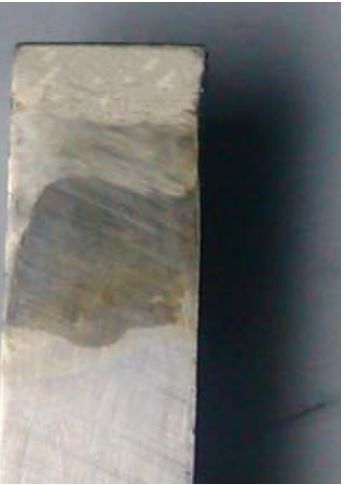

(c) Polished and corrosion

Fig. 5 Contrast to the rake face

\section{Before and after contrast of tool}

Fig. 5 shows morphology of the turning tool(cutting knife rake face of prior to deposition, after the deposition and rubbed down by oil stone, that is corrupted by $4 \%$ nitric alcohol.

From Fig. 5 before and after deposition mutual comparison, we can see the roughness of the deposited layer surface is significantly increased, that can not meet the needs of tool processing. Utilize oil stone to rub the face until it can adapt to the use of the turning tool. The tool surface topography of figure $\mathrm{c}$ which is corrupted for $2 \mathrm{~min}$ can be divided into three parts, from top to bottom, deposition layer district, affected zone and turning tool matrix.

Comprehensive seen, the hardness of the deposited layer has improved significantly, acid resistance better than the matrix, After rubbing down the sediment, the tool may satisfy the requirements of using in processing. So electro-spark deposition technique can be used to repair the tool chipping.

\section{CONCLUSION}

- As voltage $80 \mathrm{v}$, the deposition frequency $3000 \mathrm{~Hz}$, sedimentary capacitance $150 \mu \mathrm{F}$ and deposition time of $2 \mathrm{~min}$, the deposition layer thickness gets to $84 \mu \mathrm{m}$.

- Under the present experimental conditions, we obtained the maximum hardness of the deposited layer is $1487.5 \mathrm{Hv}$ which is 1.7 times than matrix's $(875.3 \mathrm{Hv})$

- Because of electro-spark deposition technology, the deposited layer and the substrate merging have better performance and stronger acid resistance than matrix. 


\section{REFERENCES}

[1] Cheng Haiyi. Turning tools wear characteristics $[\mathrm{J}]$. Mechanical Engineers.2009,3: 30-32

[2] Han Buyu. Metal cutting tool [M] . Beijing: Machinery Industry Press, 2002 .

[3] Zhao Hong, Yu Shichao. Modern tool and CNC grinding technology[M ]. Beijing: Machinery Industry Press, 2009. 10.
[4] He Ning,Hou Hongling,Bai Haiqing. Turning tool rake face sharpening strength[J] . Machine Tool \& Hydraulics.2011, 39(5):32-34

[5] Jing Enhe. Turning tool and application examples[M ]. Beijing: Chemical Industry Press, 2006. 3

[6] E Kusano, A. Satoh, M. Kitagawa, H. Canto, A. Kinbara, Titanium carbide film deposition by DC magnetron reactive sputtering using a solid carbon source, Thin Solid Films 343-344 (1999) 254-256. 